\title{
English-teaching Classroom Teaching Model Based on Ability-oriented SPOC for Higher Vocational Hotel English
}

\author{
Zhu Gong \\ Sichuan Vocational and Technical College, Suining, 629000, China.
}

\begin{abstract}
Keywords: SPOC, e-learning platform, employability, student management, hotel English,
\end{abstract} classroom teaching mode, evaluation model.

\begin{abstract}
At present, university hotel English is oriented toward knowledge-based teaching, and classes are taught in classroom teaching. The teacher-centered classroom is taught in a one-way indoctrination style of teaching. This results in the elimination of the enthusiasm of the vast majority of students for self-study, the disruption of the regularity of student learning, and the deepening of students' utilitarian concepts. Stimulation eventually leads to the consuming of teachers' enthusiasm for teaching. As a result, students' gains in the classroom are reduced. Satisfaction with teachers' teaching is also greatly reduced. Introducing information technology to integrate SPOC with flipping classrooms reforming tourism English teaching, providing intelligent, personalized and diversified mobile learning and management methods for tourism English classroom teaching. Cultivate students' professional quality and improve tourism English teaching effectiveness.
\end{abstract}

\section{Introduction}

The teaching process is basically manipulated by teachers. At present, many colleges and universities in the classroom teaching process - teaching plan, content design, schedule, etc., are completely completed by the teacher one person, the teacher one person plays the answer in the process of teaching doubters, course managers, teaching research instructors, artificially The end of the course of a class is considered to be the completion of a teaching task while ignoring the participation of the student body. The role of the student's main role was replaced. There was no pre-learning knowledge and data collection before class so that there was a gap between the student and the teacher during the class. The teaching content is rigid. In the process of classroom instruction design, teachers presuppose the time and place of students' classes, the objects they face, and the materials they use. Under this prescriptive psychological control, instructional design will become fixed and immutable, and there will be no innovation. It is even more difficult to combine theory with practice and tap new knowledge in teaching content. Over time, students cannot be informed of the latest developments in this knowledge, and the enthusiasm, innovation, and overall quality of learning are reduced. Learning is not practical. Students' learning is mainly centered on textbooks. They mainly focus on book knowledge, and they do not pay attention to the cultivation of knowledge applications and abilities. They are not practical and application-oriented, and they are not very good at cultivating students' ability to be qualified for future career positions.

The SPOC was translated as "Small-scale Restrictive Online Courses". This concept was first proposed by Armando Fox, the head of MOOC at the University of California, Berkeley, in 2013. Compared with MOOC, SPOC's restrictive entry conditions can refine the number, specialty, and characteristics of learners, which is of great benefit for improving the effectiveness of teaching and reducing the high MOOC dropout rate. Secondly, the small scale of SPOC learning facilitates the "one-to-one" exchange between teachers and students. The unique chemistry environment created by SPOC can give learners a deep and complete learning experience. Again, the combination of SPOC's "Understanding Online Learning" approach not only demonstrates the strengths of MOOC, but also makes up for the shortcomings of MOOC and traditional classroom teaching. "Human-computer interaction" is also "everyone's interaction.".

According to Bloom, the famous educator in the United States, most students' learning ability, learning speed, and motivation for further learning become very similar when they provide students 
with favorable learning conditions. Based on an in-depth study of SPOC and blended learning, it is found that SPOC can provide learners with more favorable learning conditions. Its comprehensive online and offline curriculum model and advanced curriculum platform design reduce the difficulty of blended learning for the smooth development of mixed teaching to provide protection. Realize the "four-ring interactive" high vocational English mixed teaching mode. A well-designed teaching model that meets the characteristics of higher vocational students is an important prerequisite for ensuring the effectiveness of teaching. The "four-ring interaction" vocational English blended teaching model consists of pre-department guidance, classroom teaching, post-class application, and comprehensive assessment. It is the result of the deep integration of foreign language teaching theory and network information technology. In the pre-learning phase, teachers design detailed lesson learning tasks based on teaching objectives and teaching content. The task list includes course learning videos, the use of knowledge points, difficulties in key combing, etc. It is the "small tutor" that students have plans to conduct SPOC online self-study. Students can gradually move from shallow learning to deep learning by completing various online learning tasks on the task list and combining the personalized guidance of the whole process of the teacher.

\section{The Proposed Methodology}

\subsection{The Origin and Interpretation of SPOC.}

The MOOC frenzy that erupted in the field of education has exerted a tremendous impact on traditional education. At the same time, it also brings three pressures on the education sector, that is, it is not conducive to the improvement of individualized teaching quality, is not conducive to the realization of the value of intrinsic education, and is not conducive to university education. The current status of essential functions needs to be changed.

SPOC organically combines MOOCs, micro-curriculums, minority teaching, and intensive education, which can significantly improve teaching effectiveness and is recognized by famous high schools such as Harvard University, Berkeley University, Tsinghua University, and Zhejiang University. Compared with Massive and Open of Small and Private of the SPOC and MOOC, "small scale" means that the number of students is limited to dozens to hundreds of people. "Private" means that the course is only open to applicants who have access conditions as the director of the MOOC Laboratory at the University of California, USA, believes that the advantage of SPOC over MOOC is that it has a pre-application process and a strict approval process. SPOC's small-scale and restrictive features can give students a personalized, in-depth learning experience, which is conducive to teachers' insight into the students' learning process, to the improvement of student engagement and interactivity, and to the improvement of personalized teaching quality.

Constructivism emphasizes that under the guidance of teachers, student-centered, students use necessary learning materials, help teachers and peers to help them actively explore and actively discover knowledge, and realize the active construction of the learned knowledge. In the flipping classroom, students are the main body of learning, and teachers play a role of mentoring. Students construct knowledge to achieve knowledge internalization and ability enhancement.

In 2013, Prof. Armand Fox offered the "software engineering” MOOCs that he set up on the edX platform to students inside and outside the university in the form of SPOC. However, the students in the school had to give a real customer service test results. Professor Fox moved this SPOC model to four other universities. All teachers watched MOOC video of “Software Engineering” before class. Three teachers used test questions, two teachers used automatic scoring, and one teacher used a combination of turning classroom and SPOC. One semester experiment shows that the SPOC model has achieved remarkable results in these four universities.

The flipping of the classroom is a process of uploading traditional lessons to knowledge and practicing internalized knowledge after the lesson: The pre-session students watch the videos produced by the teacher to learn knowledge, do simple exercises to find problems, and discuss problems in the classroom. Conduct internalization of knowledge. The flipping class was first started by the practice of two chemical teachers in Woodland Middle School in the United States, and was 
swept by the 2011 Salman Khan speech on TED and the Khan Academy it founded. Zeng Xing explored the deep learning model that combines SPOC and flipping classrooms, and summarized the combination of three types of SPOCs and flipping classrooms: MOOC video substitution mode, MOOC video and home-made video hybrid mode, and secondary development mode, the three types of mixed teaching modes that SPON and flip classrooms proposed by Zeng Xing et al. can be flexibly adopted according to the different courses and the level of students in practice.

\subsection{The Application of SPOC Mode in English Stereo Teaching.}

Micro video teaching can be used to attract students' interest and help students quickly enter the learning state. English is a foreign language and it is fundamentally different from the Chinese used in our daily lives. Therefore, in the course of carrying out the relevant knowledge of English knowledge, candidates often have the phenomenon of training and training, and they only give a theoretical overview and explanation of the characteristics of English itself. The problem lies in the level of understanding of students in English. Each student has an objective and subjective process in the process of recognizing and viewing English. In other words, the development of the teacher's own teaching and learning activities is actually based on The students themselves are based on a deep understanding of the teacher's understanding of the relevant content. Based on this reality, teachers should fully consider the students' demands and reality in order to maximize the interest of students and help them quickly enter the learning state. Specifically, when teachers in the first line of higher vocational education use related models in the process of integrated teaching, they must pay attention to and emphasize the main role and main position of the students themselves. The use of video teaching methods to quickly attract students' interest is one of them as the due meaning.

SPOC and MOOC are being recognized and used by more and more colleges and universities. There are also more and more English teachers who integrate SPOC into the teaching of hotel English and gradually abandon the traditional teaching methods to meet the teaching needs of the information age. . The teaching method of SPOC will be a reasonable combination of online and offline, breaking the traditional teaching philosophy and methods. Under the SPOC teaching method, students learn related professional knowledge through online learning, and teachers use offline methods to consolidate what they learn online. SPOC achieves mixed teaching, which is the online learning of teachers for under-teaching of students, and offline acquisition of knowledge teachers for students. This provides a better prospect for the teaching of English in the hotel. That is, teachers send English resources to the SPOC online platform. Students learn the English courses in SPOC beforehand. Students and teachers can communicate and discuss more in class. The melting and absorption of knowledge can achieve better teaching and learning results.

Under the SPOC model, teachers should first respond to students' "comprehensive assessment of learning characteristics," including learning motivation, learning expectations, learning style, learning sustainability, and will, etc., to fully grasp students' English learning information. On this basis, students are instructed to build SPOC online learning spaces that are in line with their own characteristics. In this online learning space, the degree of ease of learning resources, the progress of completing exercises, and the composition of the members of the study group are all based on the characteristics of the students. On this basis, teachers should effectively intervene, adjust, supervise, restrict, and motivate each student's learning process, guarantee the smooth development of learning activities to the greatest extent, and stimulate students' interest in learning and autonomy in learning. When giving students all-round and personalized learning guidance, teachers should also instruct students to adopt different learning strategies. The so-called learning strategy refers to learning activities that a learner points to learning objectives in combination with their own characteristics in a specific learning environment and embodies the planning and learning measures for learning. Learning strategies are not static and "learning" students are good at using different learning strategies at different stages of their learning.

\subsection{Implementation of Higher Vocational Tourism English Teaching Activities Based on SPOC Flipping Classroom.}

The flip classroom in the SPOC environment is the use of modern information technology to promote "teaching" and "learning", and is a product of the integration of "online learning" and 
"classroom teaching." The implementation of the teaching activities of the Vocational Tourism English SPOC flipping classroom takes the "theme" as the axis, focuses on the cultivation of language application ability, and constructs professional context and application context for tourism English learning.

When conducting specific teaching activities, teachers can use video clips to show the students the general present-day application forms, and they can expand the teaching of related issues based on the business application field. In this process, the teacher should have a clearer and clearer understanding of video clips. Video clips can describe the characteristic application scenarios of related sentence patterns in a vivid and sensible way.

In this issue, we focused on informing the implementation of three-dimensional teaching of business English and the in-depth application of the SPOC teaching model. In the morning, the English teacher should pay more attention to and emphasize the development of the student's own potential. The effective development of this method deeply stimulates the student's creativity. Consciousness stimulates the subjective initiative of students, allowing students to actively carry out tasks and carry out relevant learning with a shaped business English learning concept. In fact, each child is a relatively independent individual. The different realities of the students engaged in business English major study in higher vocational colleges determine the characteristics and personality of the children, and they are developed around the students' own independent personality. Teaching is necessary. Focusing on the characteristics of the group after the 90s and 00s in the new period to develop individualized teaching is based on the professional responsibility of high-school teachers themselves. The outline of English conversation scenes to deepen students' understanding of English language and culture is essentially to help students develop a sense of language in English. Children can gain a direct and effective improvement in business English skills through the full range of three-dimensional effects of the SPOC learning model. It should be noted that the application of the Business English subject itself is contextualized.

\section{Conclusion}

The SPOC model is a more effective model for modern students to learn the business English. The three-dimensional teaching model changed the traditional teaching methods and changed the traditional teaching concept. The three-dimensional business English teaching enables students to achieve a breakthrough in subjective learning, and effectively solves English learning in the field of business English teaching that focuses on theory and practice for many years. Students should be able to speak English with open hands and students' interests should be resolved. This paper proposes the novelty understanding of the research highlight that will promote the further development.

\section{References}

[1]. Wu, J. and Xin, Y., 2018. Creative English Classroom Teaching Model Considering Brain Cognition Enhancement. NeuroQuantology, 16(5).

[2]. Liu, B., 2017. 137. Multimedia Classroom and Innovation of English Teaching Model based on Web-based Learning Platform. Revisit de la Faulted de Ingeniería, 32(12).

[3]. Ayçiçek, B. and Yampa Yelena, T., 2018. The Effect of Flipped Classroom Model on Students' Classroom Engagement in Teaching English. International Journal of Instruction, 11(2), pp.385-398.

[4]. Yu, Y., 2017. An Innovative Model of College English Teaching based on Web-based Learning Resources and MOOC. Bulletin Ticino, ISSN: 0376-723X, 55(8). 